\title{
Procesos de subjetivación politica en el ciclo electoral de los movimientos populares en Argentina $^{1}$
}

\section{Processes of Political Subjectivation in the Electoral Cycle of Popular Movements in Argentina}

\section{Maria Mercedes Palumbo}

Universidad de Buenos Aires.

mer.palumbo@gmail.com

\begin{abstract}
Resumen
Este artículo analiza los procesos de subjetivación politica de militantes de base pertenecientes a movimientos populares de la izquierda independiente en la Argentina en el marco de las reconfiguraciones comportadas por el denominado ciclo electoral. Se llevó adelante una estrategia metodológica cualitativa que supuso una triangulación de técnicas. Los hallazgos muestran que la teoría política nativa articulada en torno a las categorías "la política de ellos" y "nuestra política" se reconfigura a medida que los movimientos populares despliegan tácticas en las cuales "nuestra política" juega en el campo de "la política de ellos". Esta recolocación de los movimientos en relación al Estado y a las elecciones conlleva a mutaciones en los procesos de subjetivación política de los militantes de base en términos de su definición de sí como militantes y de sus prácticas.
\end{abstract}

Palabras Clave: Ciclo electoral, Subjetivación política, Movimientos Populares, Argentina.

\section{Abstract}

This article analyzes the processes of political subjectivation of grassroots activists within independent left-wing popular movements in Argentina in the context of the reconfigurations involved in the electoral cycle. A qualitative methodology was carried out which implied the triangulation of techniques. The research findings show that the native political theory, structured in terms of "their politics" and "our politics", reconfigures as popular movements deploy tactics in which "our politics" is in the field of "their politics". This repositioning of popular movements in relation to the State and elections leads to mutations in the political subjectivation processes of the grassroots activists in terms of the definition of themselves as activists and of their militant practice.

Key Words: Electoral cycle; Political subjectivation; Popular movements, Argentina.

Articulo: Recibido el 22 de marzo de 2018 y aprobado 22 de octubre de 2018.

\section{Cómo citar este articulo}

Palumbo, M. M. (2019). Procesos de subjetivación politica en el ciclo electoral de los movimientos populares en Argentina. Reflexión Politica 21(41), pp. 21-34. DOI: https://doi.org/10.29375/01240781.3261 


\section{Introducción}

La sucesión de gobiernos kirchneristas en la Argentina modificó aspectos tácticos y estratégicos de la relación entre el Estado y los movimientos populares, inclusive de aquellos inscritos en la izquierda independiente. Esta categoría nativa -retomada también en trabajos académicos- actúa como marco político, ideológico, programático e identitario de la serie de movimientos y organizaciones populares "hijos del 2001" (aunque su génesis preceda temporalmente ese año para situarse en la segunda mitad de la década del noventa) que cuestionaron las tramas del neoliberalismo, mostraron un acentuado cariz territorial e impugnaron al Estado como responsable de la situación socio-económica de los sectores populares que aglutinaban. Por lo tanto, y tal como se ampliará en el desarrollo del artículo, la izquierda independiente surge de aquellos movimientos populares nucleados en la resistencia al neoliberalismo en torno a una matriz político-ideológica autonomista y a un cierto modo de pensar la política, el poder y el cambio social. Si se analiza la dinámica evolutiva de la izquierda independiente en términos de ciclos políticos, el kirchnerismo -en su doble faz de movimiento político y estatalidad-operó como un elemento condicionante.

Interesa detenerse específicamente en la etapa que denominamos el ciclo electoral de los movimientos populares de la izquierda independiente, comprendido entre los años 2011 y 2015. En efecto, esta noción constituye un hallazgo y un aporte original del trabajo de campo realizado en el marco de una investigación doctoral ${ }^{2}$ (Palumbo, 2017). Allí se analizaron las dinámicas de construcción de subjetividades políticas y epistémicas en movimientos populares del Área Metropolitana de Buenos Aires (AMBA), a partir de un estudio de casos múltiples en el Movimiento Popular La Dignidad (MPLD), el Movimiento Nacional Campesino Indígena de Buenos Aires (MNCI-Buenos Aires) y el Movimiento Darío Santillán (MDS). En el marco de esta investigación mayor, el presente artículo abordará particularmente la especificidad del denominado ciclo electoral en los procesos de subjetivación política de militantes de base de movimientos populares de la izquierda independiente del AMBA.

Los tres movimientos elegidos para la indagación nos remiten a finales de la década del noventa como contexto de génesis, encuentran en la crisis del año 2001 un hito fundante, se inscriben como parte de la izquierda independiente ${ }^{3} \mathrm{y}$ conforman organizaciones de referencia para otros movimientos populares. Por ello, sostenemos que los tres movimientos estudiados, tomados en conjunto, dan cuenta de las derivas heterogéneas del arco de movimientos populares pertenecientes a la izquierda independiente en el AMBA. Asimismo, permiten establecer un conjunto de consideraciones más amplias acerca de las particularidades de los procesos de subjetivación en el ciclo electoral. Cabe señalar la existencia de otro interesante conjunto de movimientos emplazados en el mismo recorte geográfico y con un mismo contexto de génesis que no serán objeto de atención en tanto responden a otras matrices político-ideológicas.

La búsqueda de la especificidad del período 2011-2015, en el derrotero de los movimientos populares de la izquierda independiente, devenido recorte temporal de la investigación, condujo a la nominación y caracterización del ciclo electoral. Este se abre en el año 2011 con la reelección presidencial de Cristina Fernández de Kirchner, siendo su corolario la participación en las elecciones por primera vez de gran parte del arco de movimientos pertenecientes a la izquierda independiente en el año 2015. Por lo tanto, la denominación de este ciclo político como electoral responde no tanto a su efectiva participación en las elecciones, ni a la posibilidad de trasladar su potencial de votos a sus candidatos, sino más bien al caudal de debates generados en los movimientos en indagación alrededor de la cuestión electoral y de las consecuencias político-organizativas de dichos debates.

Los replanteos del ciclo electoral involucraron nuevos desplazamientos en sus concepciones y posturas sobre el Estado, el poder, la política y las elecciones, así como transformaciones en las prácticas, las

$2 \quad$ La tesis doctoral denominada "Dinámicas de construcción de subjetividades políticas y epistémicas en dispositivos pedagógicos de formación política. Un estudio en movimientos populares multisectoriales del Área Metropolitana de Buenos Aires" se desarrolló con el apoyo de una beca doctoral otorgada por el Consejo Nacional de Investigaciones Científicas y Técnicas (CONICET) de la Argentina en el período 2013-2018.

3 Vale aclarar que, mientras el MPLD y el MDS se inscribieron directamente en esta matriz durante el recorte temporal en estudio, la fuerte herencia histórica del MNCl-Buenos Aires en este sentido persistió aun en su acercamiento a la matriz nacional-popular durante el segundo mandato de Cristina Fernández de Kirchner (2011-2015). 
tácticas y la estrategia y las modalidades de acumulación. Estas resignificaciones no son menores teniendo en cuenta la proyección en la arena electoral de actores colectivos constituidos inicialmente a distancia de la estatalidad. Si consideramos que los militantes se forman en el cotidiano de su militancia, devenida esta experiencia político-pedagógica, las reconfiguraciones ideológicas, programáticas e identitarias propias del ciclo electoral tienen su correlato en los procesos de subjetivación política de los militantes en tanto se plantean respuestas nuevas y distintas a la pregunta clásica sobre el vínculo con el Estado que requiere reencauzar consensos en la militancia.

Acorde con el objetivo general del artículo consistente en analizar la especificidad del ciclo electoral en los procesos de subjetivación política de militantes de la izquierda independiente del AMBA, las siguientes preguntas guían las reflexiones: ¿cómo se construyen los militantes de la izquierda independiente como subjetividades políticas en el contexto de las reconfiguraciones del vínculo entre los movimientos de pertenencia y el Estado? ¿Cómo operan las mutaciones en las concepciones acerca del Estado, la política y el poder a la hora de la construcción de sí como militantes y de las prácticas de un movimiento popular "independiente"?

Para ello, se siguió la decisión conceptual-metodológica de centrarse en los talleres de formación política de los movimientos en estudio como recorte de aproximación a los procesos de subjetivación de los militantes. A este respecto, consideramos que dichos ámbitos proponen explícitamente alentar, consolidar y potenciar aprendizajes políticos en sus destinatarios como objetivos de la formación; en adición, conforman tanto espacios de reflexión sistemática sobre las prácticas militantes como apropiaciones y significaciones subjetivas de las mismas. De allí que los talleres de formación política se constituyan en ámbitos sistemáticos, intensivos y bien delimitados de análisis sobre la acción política, sus lugares y sus sujetos, exhibiendo a su vez altos grados de organicidad con los movimientos de pertenencia.

Este artículo se organiza en cuatro secciones. La primera aborda las coordenadas metodológicas que habilitaron la producción de la base empírica de la investigación más amplia que sustenta los supuestos, las consideraciones y los resultados aquí esbozados. El apartado siguiente ofrece una aproximación conceptual a los lugares y los sujetos de la política, con especial énfasis en la noción de subjetividad política, desde los planteos de L. Tapia y J. Rancière. La tercera sección se aboca a la descripción del ciclo electoral en tanto marco contextual específico en el cual se busca inteligir la construcción de subjetividades políticas. El cuarto apartado presenta los hallazgos relativos a la particularidad de la subjetivación política de militantes de base en el ciclo electoral y sus tensiones respecto a procesos de subjetivación previos. A modo de cierre, las reflexiones finales recapitulan los principales argumentos del artículo y abren a nuevos interrogantes y desafíos inscritos en la actualidad de la coyuntura política argentina.

\section{Las coordenadas metodológicas de la investigación}

El interés específico por el estudio de las dinámicas de construcción de subjetividades políticas en movimientos populares es parte de una perspectiva mayor vinculada a la construcción social de sentidos que legitiman e incitan a la acción colectiva. Por lo antedicho este es un análisis adscrito en la tradición de estudios constructivistas de los movimientos sociales (Laraña, 1999), centrada en los procesos colectivos de interpretación, atribución y construcción de sentido. Desde esta óptica, se asume la existencia de una relación dinámica entre estos procesos, las oportunidades políticas y la dinámica organizacional de los movimientos.

Las consideraciones, supuestos y hallazgos presentados surgieron del desarrollo de una metodología cualitativa sustentada en la triangulación de técnicas (Forni, 2011) en el marco de talleres de formación política: la entrevista en profundidad, la observación participante y el análisis de documentos. Como se expuso en la introducción, el recorte de los talleres como ámbito particular de aproximación a los procesos de subjetivación política parte del supuesto de su condición de espacios sistemáticos de reflexión sobre la acción política, sus lugares y sus sujetos, en coherencia con los postulados más generales del movimiento en el que se inscribe.

En cuanto a la técnica de la observación participante, se realizaron observaciones en tres talleres de formación política destinados a militantes de base pertenecientes al MPLD, el MNCI-Buenos Aires y el MDS desarrollados durante los años 2012, 2014 y 2015 respectivamente. Estas 
observaciones permitieron acceder a las dinámicas de construcción subjetiva, en cuanto estaban sucediendo, así como recoger relatos retrospectivos de los militantes que reflejan sus miradas sobre sus procesos de subjetivación. Adicionalmente, se llevaron a cabo entrevistas individuales en profundidad. El criterio de selección de la muestra se basó en militantes de base que hubieran participado de los talleres de formación durante la observación participante. En todos los casos, los militantes a entrevistar surgieron de los acuerdos con las organizaciones. Las entrevistas se realizaron entre los años 2013 y 2015 en los meses inmediatamente posteriores a la finalización de cada uno de los talleres. Recuperar el punto de vista de los militantes de base implica recoger una mirada particular: la de sujetos pertenecientes a los barrios populares de las periferias del AMBA y, en la mayoría de los casos, de incorporación relativamente reciente a los movimientos. En consecuencia, se encontraban reconstruyendo -y potenciando- sus trayectorias de militancia. Esta condición de base de los militantes agrega un nuevo elemento en la indagación de los procesos de subjetivación política en el marco del ciclo electoral.

En cuanto al análisis de documentos, se recopilaron dos tipos de fuentes secundarias producidas en el recorte temporal en estudio (2011-2015): por un lado, documentos relativos a los talleres de formación política analizados tales como materiales de estudio (cuadernillos y textos) y planificaciones de los encuentros realizadas por las coordinaciones; por otro lado, documentos más generales producidos por los movimientos. Estos documentos sitúan a los talleres de formación y los procesos de subjetivación de los militantes en el marco político-pedagógico más amplio del movimiento que se encuentra anclado, a su vez, en una coyuntura social, política y económica determinada. Cabe notar que el análisis documental fue una técnica central a la hora de dar cuenta de los deslizamientos en los posicionamientos en torno al poder, al Estado y la política que dieron lugar a la generación de la categoría de ciclo electoral recuperada en este artículo.

Teniendo en cuenta la multiplicidad de espacios-momentos de construcción de subjetividades en la militancia al interior de los movimientos, la base empírica fue recogida en el recorte particular constituido por los talleres de formación política. A este respecto, consideramos a modo de supuesto que dichos talleres revisten el carácter de analizadores de las prácticas cotidianas de los movimientos populares en tanto implican un retiro temporario de la urgencia de la militancia y un tiempo específico -acotado e intensivo a la vez- para dedicarse a la reflexión sistemática sobre la acción (Palumbo, 2014). En estos talleres, los procesos subjetivos que transitaron y continúan transitando los militantes de base al interior de la organización son puestos constantemente en debate y reflexión.

\section{Los sujetos y lugares de la política}

En esta sección, interesa reponer las consideraciones de L. Tapia en diálogo con J. Rancière acerca de los lugares de la política y la centralidad de la constitución de los sujetos de la política. Este abordaje conceptual permite comprender la novedad del ciclo electoral de los movimientos populares de la izquierda independiente al ubicarlos "entre" los no-lugares de la política, aunque cabe aclarar profundamente políticos, y la disputa en los escenarios de la política institucionalizada. Las experiencias de vinculación entre movimientos populares y Estado durante los gobiernos kirchneristas, las incursiones de los movimientos en la arena electoral y el ingreso de militantes al Estado por medio de la ocupación de cargos en la administración pública nos advierte acerca de una mirada compleja de los ciclos políticos. En este sentido, estos movimientos populares surgidos y emplazados en los no lugares de la política se encuentran disputando los lugares estabilizados de la política.

Las sociedades modernas postularon al Estado -el Estado-nación moderno/colonial y liberal, trayendo a colación a Quijano (2000) - como el espacio privilegiado de la política. En consecuencia, el Estado se erigió en forma de concentración y monopolio de la política (Tapia, 2011). Este monopolio de la política consagra jerarquías de lugares, funciones, sujetos y saberes y asigna a los sujetos cierta distribución de participaciones. No solo implica el confinamiento de la política a sus lugares estabilizados -concretamente, el ámbito estatal- sino también la proclamación de "los políticos" como sus sujetos exclusivos; en paralelo a la reducción de la democracia a método de selección y renovación de políticos con un fuerte componente delegativo. Los sujetos gobernados -los ciudadanosdelegan su soberanía a intervalos regulares con 
ocasión de la celebración de elecciones, sellando así su relativa ausencia de la política.

Por su parte, la sociedad civil aglutina un conjunto de lugares en los cuales se articula una vida política no estatal que, no obstante, funciona como mediadora o puente hacia el Estado y acepta tendencialmente las normas del orden social y político (Tapia, 2011). Cuando los sujetos y prácticas de la sociedad civil desbordan esos lugares estables de la política, aparece la política de los movimientos populares. Una política potencialmente de desborde respecto a las jerarquías de lugares, funciones, sujetos, saberes y distribución de participaciones. En efecto, conceptos como ciudadanía y sociedad civil revisten un carácter polisémico, polémico y controvertido en tanto resultan claves en la garantía de la concentración y monopolio de la política al tiempo que también pueden enmarcarse en una tradición de la lucha social (Álvarez Enríquez, 2017).

Resulta pertinente la observación realizada por Tapia (2011) en torno a las posibilidades de surgimiento de una política de los movimientos populares en los no lugares de la política. En esta línea, la cuestión clave se juega en una acción intencionada: la constitución de los sujetos que opera en el cruce entre los campos de la política y la pedagogía (Palumbo, 2014; Palumbo, 2017). En el marco del monopolio y la concentración de la política, se conforman dos sujetos prototípicos. Los gobernantes y los gobernados se diferencian en su capacidad de (re)producción del orden social y político imperante. Ahora bien, esta escisión entre gobernantes y gobernados no es fija ni establecida de una vez y para siempre, pudiendo hallarse reconfiguraciones y tránsitos entre estos dos sujetos prototípicos. En palabras de Tapia,

La cualidad en la constitución es decisiva, o sea, si los sujetos se constituyen como gobernantes o gobernados, y el cómo se reconstituyen de lo uno en lo otro o transitan de una condición a la otra, o si más bien son cogobernantes. (2011, p. 75)

Por lo tanto, los procesos de constitución subjetiva podrían habilitar una política donde algunos gobernados, buscando cambiar su lugar político y social, transformaran la política misma.

Por su parte, Rancière (2012) -a quien Tapia (2011) pone en diálogo en sus propios escritos- coincide en la centralidad de la mirada sobre los sujetos. Casi de modo especular a la sentencia de Tapia (2011, p. 75) acerca de que "la cualidad en la constitución es decisiva", señala que "la política es asunto de sujetos, o más bien de modos de subjetivación” (Rancière, 2012, p. 52). Desde esta perspectiva, las subjetividades políticas se encuentran surcadas por una duplicidad al inscribirse en un espacio doble donde se juega la identificación tanto como la subjetivación. Esto es, las subjetividades pueden ser constituidas heterónomamente por relaciones de saber-poder con efectos de sujeción y fijación identitaria -es decir, identificaciones-, o bien pueden construirse con mayores grados de autonomía. En este segundo caso, las subjetivaciones implican desplazamientos, problematizaciones y reconfiguraciones en el contexto de experiencias singulares y colectivas que postulan un conflicto en el campo de lo común (Fjeld, Guintana y Tassin, 2016).

La dupla identificación-subjetivación resulta fecunda en tanto nos coloca en el terreno mismo de los sujetos gobernados y sus procesos de constitución subjetiva. De allí se siguen dos consecuencias. En primer lugar, aun en las identificaciones -la constitución "normal" de los sujetos gobernados-, la subjetividad es producida por los propios sujetos que responden y aceptan la interpelación de una narrativa y una relación que los posiciona en su condición de sujetos gobernados. Según Chaterjee (2008), que sigue una perspectiva que está lejos de la pasivización, los sujetos gobernados intervienen en la forma en la que quieren ser gobernados. En segundo lugar, la subjetivación involucra complejos procesos y tránsitos inconclusos si asumimos la definición ranceriana del concepto como:

(...) la producción mediante una serie de actos de una instancia y una capacidad de enunciación que no eran identificables en un campo de experiencia dado, cuya identificación, por lo tanto, corre pareja con la nueva representación del campo de la experiencia. (Rancière, 2012, p. 52)

Si la subjetivación política designa un proceso y no un estado, no existen sujetos inherentemente gobernados o gobernantes sino más bien un devenir-gobernado y un devenir- gobernante. Tanto Tapia (2011) como Rancière (2012) encuentran en la subjetivación un sentido profundamente democrático en cuanto perturba la normalidad de los lugares, los nombres, los sujetos y las participaciones políticas. En tanto se considera que el cotidiano de la 
militancia se torna experiencia político-pedagógica, al interior de los movimientos populares tienen lugar -y también se buscan fomentar- procesos de subjetivación. Los movimientos conforman, en consecuencia, un espacio -entre otros- de deconstrucción, reconstrucción y co-construcción de subjetividades políticas.

\section{Sobres los movimientos populares de la izquierda independiente en el AMBA en el ciclo electoral}

El análisis de la construcción de subjetividades políticas en clave de identificación y subjetivación implica aceptar que los sujetos no están dados, constituyéndose en el contexto del marco políticopedagógico de los movimientos populares y en instancias específicas eintencionales comolos talleres de formación política. Atender a los ciclos políticos resulta relevante para indagar en la especificidad de los procesos de subjetivación, mientras se tenga en cuenta los cambios, inflexiones y corrimientos que atravesaron la dinámica de los movimientos populares de la izquierda independiente.

Según Svampa (2010), las matrices políticoideológicas son:

Líneas directrices que organizan el modo de pensar la política y el poder, así como la concepción del cambio social. Si bien cada matriz políticoideológica posee una configuración determinada, los diferentes contextos nacionales, así como las tensiones internas las van dotando, para cada caso, de un dinamismo y una historicidad particular. (p. 8)

Respectoalas matrices más representativas de los movimientos populares contemporáneos en la Argentina, cabe señalar la matriz propia de la izquierda tradicional partidaria, la nueva narrativa autonomista y la nacional-popular (Svampa, 2010; Svampa y Pereyra, 2004). Estas tres matrices se distinguen -al menos en su estado puro- en relación a los límites y las potencialidades que presenta el Estado y la sociedad como espacios de canalización del conflicto (Longa, 2017).

Por lo tanto, los movimientos a los cuales se refiere este artículo se conectan con un modo organizativo particular no generalizable a todas las organizaciones territoriales del AMBA. La matriz de la nueva narrativa autonomista es nombrada aquí como izquierda independiente acorde con las categorías que estos movimientos han seleccionado para describirse a sí mismos durante el ciclo electoral. El deslizamiento de la idea de izquierda autónoma, más propia del contexto de resistencia al neoliberalismo, hacia izquierda independiente connota las reelaboraciones tácticas y estratégicas en curso. De lo anterior se desprende la fuerte redefinición sufrida por el concepto de autonomía en los movimientos integrantes de la nueva narrativa autonomista. Desde sus primeras concepciones en las que planteaban la autonomía como radical exterioridad y ajenidad con la estatalidad, influenciada de modo notable por el ideario y las prácticas zapatistas, hasta la actualidad del ciclo electoral donde la marca identitaria ligada a la autonomía es significada como un resguardo, de la independencia en la toma de decisiones sobre las tácticas y estrategias a seguir, que admite la participación en los lugares estabilizados de la política. En la citada investigación doctoral de Palumbo (2017), se propuso una cronología de los ciclos políticos de los movimientos de la izquierda independiente a partir de las interrelaciones e interdependencias con la política institucional. El ciclo resistencialista (1997-2002), momento de génesis de los movimientos populares en estudio, estuvo signado por la oposición al neoliberalismo y la impugnación de la política. Allí los movimientos mostraron una naturaleza destituyente que estaba dada por su capacidad de veto popular desde un posicionamiento como actores lejanos a la disputa institucional. Al ciclo resistencialista le sucedió el ciclo territorial ${ }^{4}$ (2003-2011) que planteaba la construcción positiva de un orden alternativo desde las barriadas populares. La construcción de poder popular funcionó como concepto y praxis de transformación cotidiana en los territorios. La marca distintiva de este ciclo estuvo dada por la centralidad asumida por el territorio y los frentes territoriales en el marco de la encrucijada planteada entre lo destituyente, propio del ciclo resistencialista, y lo (re)instituyente. Finalmente, el ciclo electoral

$4 \quad$ La noción de ciclo territorial se retoma -y resignifica- del análisis realizado por Longa (2013) de los ciclos políticos institucionales y los ejes de acumulación del Frente Popular Darío Santillán. El ciclo territorial lo sitúa particularmente en el período que va desde su fundación en el año 2004 hasta el año 2007. Para el autor, el principal eje de acumulación política de este ciclo se basó en la incorporación de grupos, movimientos y colectivos a partir de sus características específicamente territoriales. De allí que el sector territorial demostrara el mayor dinamismo en este ciclo. 
(2011-2015) alude al caudal de debates surgidos en los movimientos en torno a la participación en las elecciones que se concretaron en el año 2015.

La caracterización del ciclo electoral de los movimientos populares de la izquierda independiente requiere ser comprendida en sus mutuas imbricaciones con la estatalidad. Este ciclo se abre con la contundente reelección presidencial de Cristina Fernández de Kirchner en el año 2011, que obtuvo el 53.9\% de los votos; ${ }^{5}$ con esto se reafirmó la legitimación estatal que trajo aparejada la consolidación del kirchnerismo (Longa, 2017). Adicionalmente, la apertura del ciclo electoral se enmarca en un cierto reflujo por la acumulación política en los frentes territoriales de los movimientos de la izquierda independiente que supieron ser la base social preponderante de los mismos. Este reflujo podría deberse, en parte, a la recomposición económica y laboral lograda durante los gobiernos kirchneristas. El escenario descrito reafirmó la inquietud de estos movimientos por dilucidar si lo electoral permitiría realizar un salto en la construcción de poder popular, que articulara la prefiguración de la sociedad futura en los territorios con la disputa en el seno de las instituciones estatales. En este planteo, la lucha electoral se presentaba como un "capítulo subordinado, pero imprescindible en la construcción del socialismo y la ampliación del protagonismo popular" (Stefanazzi Kondolf, Mosquera y Spadavecchia, 2015, p. 41). La opción electoral traducía en nuevos términos y con fuerza renovada la cuestión del Estado, presente desde el ciclo resistencialista (1997-2002).

Las vinculaciones con el Estado no eran novedosas al considerar las variadas acciones directas realizadas con miras a generar impactos en la estatalidad y el efectivo acceso a ciertas políticas públicas por parte de los movimientos de la izquierda independiente. Si bien los limites entre movimientos y política institucional fueron difusos desde el ciclo resistencialista, la participación en elecciones en centros de estudiantes, comisiones internas de fábricas y cuerpos de delegados de villas, avanzado el ciclo territorial (2003-2011), los había vuelto más lábiles. Empero, el ciclo electoral instalaba el dilema de la participación en la institución clásica y central de la política representativa: las elecciones generales. Este dilema es sintetizado por F., referente de una cuadrilla de trabajo del MLPD como "jugar a lo grande en la política" y "disputarle al gobierno en su campo" (F.1., comunicación personal, 24 de julio de 2013). ${ }^{6}$

Tal como se señaló en la Introducción, la denominación ciclo electoral hasta el año 2015 responde no tanto a la efectiva participación en las elecciones por parte de los movimientos en estudio, ni a la posibilidad efectiva de trasladar su potencial de votos a sus candidatos, sino más bien al caudal de debates generados en torno a la cuestión electoral. Las consecuencias políticoorganizativas de estos debates involucraron nuevos alineamientos, creación de herramientas electorales ad-hoc y hasta escisiones. ${ }^{7}$ Desde la perspectiva que sostenemos, el ciclo electoral se comprende como una respuesta a la consolidación del kirchnerismo en su doble condición de estatalidad y movimiento político (Sidicaro, 2011). ${ }^{8}$ Implicó, inclusive, un balance crítico respecto a las potencialidades y limites de inscribirse en la izquierda independiente como denominación político-ideológica, identitaria y programática. En este balance se impuso el diagnóstico relativo a la necesidad de romper el

$5 \quad$ La contundencia de la elección se debe al porcentaje de votos que evitó el desarrollo de una segunda vuelta, a los más de 30 puntos de diferencia entre la fórmula ganadora y el segundo candidato (Hermes Binner obtuvo el 16.8\%) y a la victoria en todas las provincias del país con excepción de San Luis. Más allá de este triunfo, ya se comenzaba a desplegar la contraofensiva neoliberal y a evidenciarse los límites endógenos de los gobiernos populares para generar procesos de cambio profundo.

6 De acuerdo a lo pactado con los movimientos, los nombres y apellidos de los entrevistados se mantendrán en anonimato.

$7 \quad$ A este respecto, el debate intelectual sobre las elecciones se abre con el artículo "Una incitación a la incomodidad. Nueva izquierda y disputa institucional" de M. Ogando en el número 2 de la Revista Batalla de Ideas y las réplicas publicadas en el siguiente número (AA.VV., 2012). Posteriormente, el libro Ensayos políticos. Debates en torno al poder, la organización y la nueva etapa (AA.VV., 2015) compila preguntas y reflexiones de intelectuales de distintos movimientos de la izquierda independiente en relación a la intervención en la política institucional y la conformación de partidos desde los movimientos populares.

8 Siguiendo a Sidicaro (2011), el kirchnerismo puede ser leído como la gestión gubernamental extendida entre los años 2003 y 2015 y como el movimiento socio-político integrado por un conjunto heterogéneo de sectores políticos e ideas identificadas con Néstor Kirchner y Cristina Fernández de Kirchner. Sin desconocer la riqueza del análisis del kirchnerismo como movimiento político, en este artículo se utiliza principalmente la denominación kirchnerismo como sinónimo de gestión gubernamental. 
techo de la izquierda independiente (Longa, 2013) en consonancia con la pérdida de gravitación de los frentes territoriales.

El saldo de estos debates fue disímil, pues generó distintos posicionamientos en relación con los ritmos, las formas y los actores de la disputa en la arena electoral. En cuanto a los movimientos en estudio, los tres participaron de las elecciones del año 2015. ${ }^{9}$ El MNCI-Buenos Aires se involucró activamente en la campaña nacional del Movimiento Evita que apoyó al Frente para la Victoria (FPV) y a Daniel Scioli como candidato de la continuidad de los gobiernos kirchneristas. Por su parte, el MPLD y el MDS integraron el Frente de Izquierda y de los Trabajadores (FIT), frente conformado por partidos de la izquierda trotskista. En ambos casos se ocuparon cargos no expectables en las listas del FIT.

Cabe notar que esta primera experiencia electoral se articuló en torno a los armados de partidos tradicionales que respondían a dos matrices político-ideológicas distintas: la de la izquierda tradicional partidaria en el caso del FIT y la nacional-popular en el caso del FPV. La coordinación entre la izquierda trotskista y las fuerzas políticas de los movimientos de la izquierda independiente se presentó como una novedad en la historia de los ciclos políticos de estos movimientos que habían rechazado históricamente -de modo radical en el ciclo resistencialista (1997-2002)- el verticalismo de los partidos de izquierda. Desde la mirada de algunos militantes, la intervención en lo electoral desde estos armados tradicionales resultó limitada en términos de la apuesta expresada por prefigurar lo electoral. En este sentido, consideramos que la participación en estos frentes debe leerse como parte de un proceso de experimentación política que incluye la construcción -en proceso- de herramientas político-electorales propias "desde abajo y a la izquierda". ${ }^{10}$ En este sentido, el MDS lanzó Pueblo en Marcha ${ }^{11}$ en el año 2014 e Izquierda
Popular fue creada por el MPLD en el año 2016, ambos en la Ciudad Autónoma de Buenos Aires.

De acuerdo con Longa (2017), planteamos que la relegitimación de la esfera institucional durante el kirchnerismo, como ámbito privilegiado para la regulación de numerosos aspectos de lo social, modificó las perspectivas tácticas y estratégicas de los movimientos populares, aun en aquellos que respondían a la izquierda independiente. Por lo tanto, y aquí hallamos una interesante parábola, si en el ciclo resistencialista (1997-2002) los movimientos adoptaron la impugnación del Estado en sus consignas y métodos de lucha (incluidos aquellos de matriz nacional-popular), el ciclo electoral nos sitúa en una estrategia política orientada a la participación en el Estado y sus instituciones políticas (incluidos aquellos de matriz de izquierda independiente). Esto conlleva una combinación de acción política directa y acción política institucional, tal como versó el lema del MDS en la campaña electoral del año 2015: tener "un pie en las instituciones y miles en las calles»; ${ }^{12}$ esto es, un pie en la lucha estatalelectoral y otros muchos en la construcción de poder popular en los territorios. A este respecto, un referente del MPLD sostuvo: "Nosotros apostamos a una nueva mediación, a hacer propias las políticas institucionales, es decir, cuestionar que se estén discutiendo propuestas de políticas públicas y no tener ninguna mediación". ${ }^{13}$

A modo de síntesis, el ciclo electoral generó la revisión de consignas, posiciones y lineamientos arraigados en las bases sociales de los movimientos populares que incluían un cierto rechazo a la política electoral, herencia del contexto resistencialista de génesis. La dimensión contextual que aporta la particular coyuntura del ciclo electoral no debe ser soslayada a la hora del análisis de los procesos de subjetivación política en militantes de base pertenecientes a los movimientos populares de la

$9 \quad$ Así, el MDS transita el camino recorrido por el Movimiento 26 de Junio (otra organización del FPDS "a secas") en las elecciones del distrito de Rosario en el año 2013 desde el Frente Ciudad Futura. En el año 2015, acceden legisladores del Frente Ciudad Futura al Concejo Municipal de Rosario.

10 Esta categoría utilizada en la jerga militante durante el período en estudio reenvía a la famosa consigna del Ejército Zapatista de Liberación Nacional.

11 Pueblo en Marcha se encuentra compuesto por la Regional Capital del FPDS, Democracia Socialista, Movimiento por la Unidad Latinoamericana y el Cambio Social (MULCS) y el Avispero.

12 Este slogan fue utilizado en la campaña electoral de Pueblo en Marcha, herramienta electoral en construcción de la que participa uno de los movimientos populares analizados.

13 Aznárez, C. (2017). "Al palacio entramos todos o no entra ninguno". Resumen latinoamericano, 13 de febrero de 2017. Disponible en: http://www.resumenlatinoamericano.org/2017/02/13/argentina-entrevista-a-rafael-klejzer-referente-delpartido-izquierda-popular-al-palacio-entramos-todos-o-no-entra-ninguno/ 
izquierda independiente; máxime teniendo en cuenta una historia previa que tensionan las subjetivaciones hacia lugares y posicionamientos distintos en relación a la autonomía y la institucionalidad (tal vez, en una línea menos estatalista).

\section{La construcción de subjetividades politicas en el ciclo electoral}

Uno de los supuestos que se sostienen en este artículo reside en la existencia de una especificidad en los procesos de subjetivación política que está dada por su situacionalidad. Las características ya descritas del ciclo electoral inciden en los procesos de subjetivación política dado que la asunción de la dimensión política de la militancia es paralela a la recolocación de los militantes de base en relación con el Estado y la política electoral y, en adición, acompaña el reposicionamiento del movimiento de pertenencia y de la propia izquierda independiente en su conjunto.

\subsection{Nuestra politica y la politica de ellos}

A lo largo del trabajo de campo realizado, emergió lo que puede ser considerado como una teoría política nativa construida por los militantes desde el uso de los pronombres ellos y nosotros. Esta teoría política nativa se centraba en la distinción entre la "política de ellos" y "nuestra política". ${ }^{14}$ Esta distinción parece correr en paralelo a la delimitación ya presentada, propia de la literatura especializada, entre los lugares estabilizados de la política y los (políticos) no lugares de la política. La "política de ellos" es significada por gran parte de los militantes desde la desconfianza en tanto su presencia intermitente en las barriadas populares no termina de resolver sus necesidades, tal como lo expresa una militante de base del MPLD: "para ellos [los políticos] los pobres no existen y los pobres sí existimos" (M.1., comunicación personal, 12 de abril del 2013). En este sentido, "la política de ellos" se vincula directamente a los funcionarios estatales e incluye selectivamente -y con ciertos matices- a los punteros políticos, al abanico de fuerzas de seguridad con presencia en los barrios, a los "transas" 15 y organizaciones sociales que reproducen lógicas homologables a la red de prácticas clientelares. Por su parte, "nuestra política" nomina las características y lógicas de pensar y practicar la política propia de los movimientos populares. La mención a la política como "arma para la defensa del pueblo" (M.2., comunicación personal, 24 de julio de 2013) sintetizó uno de los sentidos demarcadores de "nuestra política" en tanto esta se propone defender al pueblo y avanzar con la organización y la lucha de modo que arranque a los gobiernos -o consiga, dependiendo de las matrices político-ideológicas- ${ }^{16}$ lo que les corresponde y "la política de ellos" les está privando. Esta intencionalidad convierte a "nuestra política” en herramienta de transformación.

En torno a esta distinción ${ }^{17}$ los militantes montan la impugnación al monopolio de cierta política (la de ellos), la recuperación y reinvención de la legitimidad de otra política (la nuestra) construida desde la diferenciación con la primera; $y$, en consecuencia, la asignación -no exenta de resistencias- de una dimensión de politicidad a sus propias prácticas que les permite asumir que la política es posible, necesaria e indispensable para la vida de los sujetos. Y este juego de diferenciaciones surge de la experiencia concreta de los militantes en su vínculo cotidiano con los actores políticos barriales, de sus trayectorias de militancia en organizaciones y movimientos con lógicas disímiles de construcción política y de su reflexión individual y colectiva respecto a la política.

14 El uso de comillas de aquí en adelante identifica los términos nativos surgidos del trabajo de campo realizado.

15 Esta expresión se utiliza para referir a los sujetos que están a cargo de la intermediación en el negocio de la venta de drogas, asociados a lo que se denomina en Argentina "narcomenudeo". A menudo, estos sujetos pertenecen al mismo barrio y despliegan contactos con los punteros políticos y/o las fuerzas de seguridad.

$16 \quad$ La distinción entre "arrancar" y "conseguir" en el lenguaje de los actores se vincula a los lugares de mayor o menor externalidad respecto a la estatalidad en la cual se sitúan los movimientos populares en relación a las matrices políticoideológicas de las cuales son tributarios.

17 Allende la reiteración de las ideas de "nuestra política" y "la política de ellos", aparecieron otro conjunto de significaciones binarias para distinguir la política de los movimientos de otra política: la política del movimiento y la política partidaria/la política de los funcionarios (S.1., militante del MDS); la política que hay que construir y la política en general (M.3, militante del MDS); la política distinta a lo tradicional y la política tradicional (T.1., militante del MDS); nuestra política y la política del gobierno/del programa gubernamental (M.1., militante del MPLD); la política nuestra y la política de la vereda de enfrente (G.1., militante del MPLD); la política del movimiento y la política de afuera (A.1., militante del MNCl-Buenos Aires). 
En los talleres de formación política analizados, los militantes relataban el movimiento subjetivo de reconocimiento de la dimensión de politicidad de la experiencia militante y la asunción de sí como subjetividades políticas. Este movimiento implica abrazar "nuestra política" y compartir un cierto relato del mundo - del pasado, el presente y el futuro- en función del cual orientar las prácticas. Así, desandaban concepciones de la política vinculadas a una imposición desde afuera y desde arriba, connotando siempre sentidos negativos en la equivalencia de la política con "la política de ellos". Este tránsito era interpretado como un antes y un después que combatía el desinterés o apatía por la política y que no coincidía necesariamente con el momento de ingreso a los movimientos en tanto "cuesta reconocer que en el movimiento se hace política" (T.1., comunicación personal, 25 de septiembre de 2015). D., militante de base del MDS, es elocuente al reponer las resistencias a la política -y su propia metamorfosis- y, asimismo, puntualizar la existencia de un equívoco en relación a la interpretación del discurso de los movimientos populares de rechazo a "la política de ellos" como rechazo a la politica in toto:

Mucha gente del movimiento dice "yo no creo en la política". Sí yo creo, yo creo en la política, en la política como nosotros la construimos, no en la política que hace el burócrata o los capitalistas. En eso yo no creo, no creo. Pero sí creo en la política que nosotros construimos todos los días ¿entendés? Con el mínimo aporte que nosotros hacemos, estamos haciendo una política nosotros, es de nosotros, es del movimiento. Pero después, sí obvio que yo creo en la política, sí que creo. Sé que nosotros somos un movimiento político, porque es así, nosotros somos un movimiento político. Por ahí ¿viste? Claro como nosotros estamos en contra de la política se entiende mal. Hay compañeros que ponele, porque eso también es un aprendizaje, yo también decía antes "no, pero nosotros estamos en contra de la política”. No, no es así. Nosotros estamos en contra de cómo el sistema se maneja en la política. Pero nosotros también hacemos política de otra manera. Entonces sí que creemos en la política. (D.1., comunicación personal, 22 de agosto de 2015)

En esta línea, cabe problematizar cierta dificultad observada en algunos entrevistados para dar cuenta de que "en el movimiento se hace política”, expresada a partir de intervenciones de militantes que sentenciaban categóricamente "lo mío no es la política” (A.2., comunicación personal, 28 de agosto de 2015) o "yo no entiendo mucho de política” (K.1., comunicación personal, 25 de septiembre de 2015; G.1., comunicación personal, 15 de mayo de 2013). Las razones intervinientes son múltiples; por un lado, aluden a concepciones de desconfianza ${ }^{18}$ y ajenidad en relación a "la política de ellos" que se traducen en un cierto cuidado, distanciamiento, rechazo y probablemente también miedo a la política toda. Por otro lado, es notable un sentido común arraigado respecto a la especialización del trabajo político que erige un modelo de sujeto con credenciales para gobernar que no coincide con el perfil de los militantes de base. Estas consideraciones planteadas por los militantes -con diversos grados de criticidad- en los talleres de formación involucraban desde el supuesto carácter "muy duro, frío y centrado" (A.2., comunicación personal, 28 de agosto de 2015) que debería exhibir el político, un lugar de disposición y circulación de los cuerpos políticos distinto al de las periferias de las ciudades por lo que aparecen frases como "jeste qué va a ser político si vive el lado de mi casa!"; ${ }^{19}$ se hace necesario un saber acreditable que habilite a ocupar cargos en tanto "el político es el que sabe"; ${ }^{20}$ y hasta una vestimenta particular de tipo formal que conduce a sostener "a mí me dicen, ¡mirá cómo te vestís... qué vas a hacer política vos!”. ${ }^{21}$ De estos comentarios se sigue la presunción de incompetencia política; algunas veces autopercibida $y$, en otras oportunidades, impuesta desde la mirada externa de acto-

18 A lo largo de las entrevistas, se relatan diversas situaciones que fundamentan la desconfianza hacia la política y, en algunos casos, se convocan para señalar las impresiones iniciales respecto a los movimientos de pertenencia. A modo de ejemplo, E. comenta que: "Desconfiaban, muchos desconfiaban de por qué ellos [en referencia a los integrantes del MNClBuenos Aires] venían. Todos decían, siempre decían, «estos tienen un sueldo, trabajan en algún lugar y ¿por qué vienen?». Esto es lo que decían: «ipor qué vienen? Nadie camina así por así»” (E.1., comunicación personal, 08 de mayo de 2013).

19 Registro de observación de la Escuelita de formación del MDS (24 de abril de 2015).

20 Registro de observación de la Escuelita de formación del MDS (24 de abril de 2015).

21 Registro de observación de la Escuelita de formación del MDS (24 de abril de 2015). 
res barriales como las familias y los vecinos..$^{22}$

\subsection{Nuestra política en la política de ellos}

El desacuerdo en torno a las definiciones de la política no solo se establece en relación a otros modos de pensar y practicar la política como el clientelismo político, por ejemplo, frente a los cuales se articula una crítica en la izquierda independiente presente desde el ciclo resistencialista (1997-2002). El desacuerdo opera en el interior de los movimientos en estudio, traduciéndose en la significación diferencial respecto al carácter social o político de las prácticas militantes como terreno de inscripción subjetivo. Los militantes "ya politizados" advierten la presencia de compañeros a los que "les falta politizarse".

El debate clásico encontrado en la literatura sobre lo social y lo político (Cortés, 2010; Natalucci, 2011; Natalucci y Pagliarone, 2013; Palomino, 2004) -en términos de los denominados tránsitos, "saltos" y vínculos entre ambas esferas- se reactualiza desde la perspectiva de la subjetividad. Se evidencia cierta heterogeneidad en la asunción de sí como subjetividades políticas por parte de los militantes de base en los movimientos en análisis, inscribiéndose diferencialmente en lo social o en lo político. A partir de las observaciones y las entrevistas realizadas, se registra la persistencia de una parte de la base social que se encuentra más "cómoda" tanto en sus discursos y sus prácticas como en la militancia social, en la resolución de los problemas asociados a "la necesidad" en el comedor, el merendero, las cuadrillas de trabajo y los proyectos productivos. Una militante señaló, desde una mirada crítica, la demarcación de espacios y temas políticos de otros concebidos como no-políticos (o sociales) al interior del movimiento. Con este fin, evocó una frase en circulación en la organización "ahora hablamos de política, ahora no hablamos de política" (Y.2., comunicación personal, 14 de agosto de 2015) ${ }^{23}$, según la cual hablar de política estaría acotado a las acciones de lucha y lo referente a las elecciones -a la herramienta electoral- mientras que los espacios y temas restantes constituirían lo otro (o lo diferente) de la política.

La disparidad en la politización se tensiona aún más en el contexto del ciclo electoral en el cual las aparentes distancias entre "nuestra política" y "la política de ellos", sobre la base de la cual operaba una marcada diferenciación, se relativizan. A la clásica tensión entre lo social y lo político, se suma otra en la incursión de "nuestra política" en "la política de ellos". Desde la perspectiva de un militante, esta incursión implica "arremangarnos los pantalones para dar la discusión y meternos en el Estado" (R.1., comunicación personal, 12 de febrero de 2015). Resulta llamativa la inversión de la metáfora usualmente empleada para referir a los funcionarios (y también a los investigadores) que se introducen en el barro de los barrios populares; en ella aparece una equivalencia entre el barro y el terreno estatal que trasluciría cierta permanencia de la concepción de "la política de ellos" como sucia (embarrada, negativa).

El gesto de disputa y reconversión de una "política de ellos", otrora solo de ellos y ahora también potencialmente nuestra, es expresada como la creación de una "política (de ellos) nueva" (S.1., comunicación personal, 31 de agosto de $2015)^{24}$. La diferencia entre "nuestra política" y "la política de ellos" ya no giraría en torno a la exclusión de ciertos territorios como lo electoral sino a los sujetos, las mediaciones políticopedagógicas, las formas de construcción y los fines intervinientes en la participación en los lugares de la política estabilizada. Así, los cambios en las prácticas políticas en el ciclo electoral trastocan el discurso en torno a "nuestra política" construido por los militantes, siempre que esta sea definida por la negativa; es decir, por el mero rechazo a "la política de ellos". Tal como se desprende de las entrevistas, resulta difícil reconfigurar un

22 Y., militante de base del MPLD, lo plantea de modo tajante: "Porque está súper instalado de que siempre tiene que haber alguien que mande, otro que va, alguien que pague, otro que cobre y así. El mundo está hecho como que... unos somos más, otros somos menos" (Y.1., comunicación personal, 29 de noviembre de 2013)

23 El fragmento completo refiere que: "La política es la capacidad de hacer y transformar y, para mí, es necesario un cambio con otros porque no se pueden cambiar cosas estructurales solo. Después está en el común de la gente que va a decir la política como la política partidaria. Pero es lo que se dice, incluso en el movimiento, se dice «ahora hablamos de política, ahora no hablamos de política», cuando en realidad todo el tiempo estamos haciendo política". (Y.2., comunicación personal, 14 de agosto de 2015)

$24 \quad$ La cita completa es la siguiente: "Pueblo en Marcha más allá de ser política, es una política nueva, es una política viste que... yo no la conocí, ni tampoco escuché hablar de una política como Pueblo en Marcha, ¿me entendés? Por eso te digo, la política de Pueblo en Marcha es distinta, es una forma de transformar... es una forma de vida también". (S.1., comunicación personal, 31 de agosto de 2015). 
discurso sobre "nuestra política" que incorpore la prefiguración en la arena electoral en términos distintos a los de "la política de ellos".

Por lo tanto, la construcción de subjetividades políticas en el ciclo electoral involucra la articulación de lo político en lo social tanto en "nuestra política" como en "la política de ellos". Este gesto es relatado como una reconciliación con la idea de la política en general y de distanciamiento de la sinonimia entre política y "política de ellos" (los funcionarios, el gobierno, los punteros). Este tránsito parece resultar más sencillo cuando "la política de ellos" y "nuestra política" se presentan -aunque nunca fue realmente así- como territorios claramente separados. Como señalamos anteriormente, los procesos de subjetivación política revisten tránsitos complejos. El ciclo electoral genera resistencias no solo en los militantes que todavía deben asumirse como subjetividades políticas -asumir la politicidad de su militancia- sino también en los militantes que ya asumidos políticos deben revertir la desconfianza hacia todo lo relacionado con "la política de ellos" para comulgar con la incursión de "nuestra política" en "la política de ellos".

La tarea de la (re)politización aparece como un lugar de llegada deseable en los términos del enfoque de la subjetivación política que aquí se suscribe. De igual modo, constituye un elemento significativo al interior de las organizaciones con las que se llevó adelante la investigación. Los movimientos populares de la izquierda independiente esperan estos tránsitos subjetivos de politicidad en sus militantes como horizonte normativo. En el trabajo de campo realizado, se registraron distintas intervenciones que apuntaban a puntualizar trayectos de politización inconclusos de ciertos militantes que tensionaban las prácticas cotidianas de quienes compartían un mismo territorio de militancia o un espacio de trabajo dentro de las organizaciones.

\section{Conclusiones}

Este artículo buscó analizar la especificidad del ciclo electoral de los movimientos populares de la izquierda independiente en los procesos de subjetivación política de los militantes de base en un recorte temporal específico que comprende los años 2011-2015. Para ello, se partió de la base empírica construida a partir de observaciones, entrevistas y análisis de documentos en talleres de formación política de militantes de base de tres movimientos populares de la izquierda independiente del AMBA. Asimismo, se utilizaron los planteos de L. Tapia (2010) y J. Rancière (2012) como abordaje categorial de aproximación a los lugares y los sujetos de la política así como a la noción de subjetividad política.

Las reflexiones compartidas se situaron en dos aspectos con imbricaciones mutuas: por un lado, la recuperación de las notas características del ciclo electoral en tanto marco contextual específico en el cual inteligir la construcción de subjetividades políticas; por otro lado, la reconstrucción de los procesos de subjetivación política de los militantes entendiendo que el ciclo electoral no opera solamente a modo de contexto general. Por el contrario, se sostuvo que las mutaciones en los planteos tácticos y estratégicos de los movimientos populares, producto de los debates entablados y las decisiones tomadas en este período, condicionaron los modos de la construcción de sí de los sujetos. Dichas mutaciones subjetivas en acto pudieron ser observadas en los ámbitos de la formación política en su condición de espacios sistemáticos de reflexión sobre la práctica.

En cuanto al primer aspecto, el ciclo electoral -leído desde un ejercicio de historización del derrotero de los movimientos populares de la izquierda independiente en el AMBA- implicó progresivas reconfiguraciones en los modos de comprender la política, el poder y el cambio social. Entre ellas, los debates internos vinculados a la efectiva participación en la política electoral y las implicancias organizativas provocadas permitieron nombrar a este ciclo como electoral, aun cuando la presentación a elecciones recién se concretara en el año 2015. Así, el empleo de la noción de ciclo electoral reviste un aporte novedoso para la literatura especializada en movimientos populares dado su carácter poco explorado, con excepción de ciertas investigaciones antecedentes como las ya citadas de Longa (2013; 2017). Esta escasa atención contrasta con los copiosos debates en torno a lo electoral al interior de la militancia tanto como con la existencia de una cantidad considerable de textos producidos por militantes para su discusión interna, o bien publicados en periódicos y portales web de organizaciones de la izquierda independiente.

En cuanto al segundo aspecto, vinculado a la subjetivación política de militantes de base, los hallazgos presentados remiten al complejo 
proceso de asunción de la dimensión política por parte de los militantes de base, acompañando el reposicionamiento de la propia izquierda independiente en cuanto a la política electoral. Por lo tanto, la construcción de subjetividades políticas en el ciclo electoral implica revertir la tajante distancia establecida históricamente entre "nuestra política" y la "política de ellos" para asumir, por el contrario, el involucramiento de "nuestra política" en "la política de ellos". El ciclo electoral genera, entonces, resistencias no solo en los militantes que todavía deberían asumirse -según el ideal normativo de los movimientoscomo subjetividades políticas sino también en los militantes que, ya devenidos políticos, deberian revertir la desconfianza hacia "la política de ellos". Estas consideraciones habilitan una reactualización del debate ya clásico en torno a la literatura especializada respecto a los tránsitos entre lo político y lo social. A este respecto, la clave de aproximación no estuvo centrada en el movimiento como totalidad sino en los procesos subjetivos de los militantes; $\mathrm{y}$, adicionalmente, situar dichos tránsitos en el ciclo electoral suma un tercer elemento al par conceptual: el de la política representativa. De allí que invite a pensar no solo el pasaje de lo social a lo político, sino aquella sinuosa trayectoria (subjetiva y colectiva) de lo político a la política.

Finalmente, y en términos de un esbozo del desarrollo futuro del fenómeno analizado a la luz de la evolución de la realidad política, si las elecciones legislativas y presidenciales de 2015 cimentaron los caminos asumidos por los movimientos populares de la izquierda independiente, cabe sostener que el ciclo electoral continúa abierto en la actualidad argentina. Desde nuestra mirada, compartida por referentes de los movimientos analizados, el sostenimiento de este ciclo más allá de su etapa germinal presenta dos grandes desafíos. El primero apunta a la consolidación de la apuesta electoral por medio de la experimentación en las formas y relaciones políticas que conjuren ciertas características específicas de lo electoral como la escisión entre gobernantes y gobernados, la verticalidad de la forma-partido y el componente delegacionista de la representación. Posiblemente, la construcción de herramientas electorales propias se erija en un elemento interesante en vistas a pensar y practicar la disputa electoral en términos de prefiguración de "nuestra política" en la "política de ellos". El segundo desafío reside en asumir y encaminar esfuerzos a la tarea de la unidad frente a la dispersión y fragmentación del campo popular que involucra el armado de frentes electorales entre distintas organizaciones y movimientos populares. Esta unidad es interpretada como una necesidad para afrontar el nuevo contexto abierto desde el año 2015 con fuerzas redobladas que se expresen en las calles y también en las elecciones.

\section{Referencias}

AA.VV. (2012). Sección Réplicas. Revista Batalla de Ideas, 3 (3).

AA.VV. (2015). Ensayos politicos. Debates en torno al poder, la organización y la etapa. Buenos Aires: El Colectivo.

Álvarez Enríquez, L. (2017). Pueblo, ciudadanía y sociedad civil. Apuntes para la reflexión sobre la dimensión de "lo social" en el siglo XXI. En Pueblo, ciudadanía y sociedad civil. Aportes para un debate. Álvarez, L. (Comp.). Ciudad de México: Siglo XXI.

Chatterjee, P. (2008). La nación en tiempo heterogéneo y otros estudios subalternos. Buenos Aires: Siglo XXI.

Cortés, M. (2010). Movimientos sociales y Estado en el "kirchnerismo". Tradición, autonomía y conflicto. En Movilizaciones, protestas e identidades colectivas en la Argentina del bicentenario. Massetti, A., Villanueva, E. y Gómez, M. (Comps.). Buenos Aires: Nueva Trilce.

Fjeld, A., Quintana, M. y Tassin, E. (2016). Introducción. En Movimientos sociales y subjetivaciones politicas. Fjeld, A., Quintana, M. y Tassin, E. (Comps.). Bogotá: UNIANDES

Forni, P. (2010). Reflexiones metodológicas en el Bicentenario. La triangulación en la investigación social: 50 años de una metáfora. Revista Argentina de Ciencia Política. (13-14), pp. 255-270

Laraña, E. (1999). La construcción de los movimientos sociales. Madrid: Alianza.

Longa, F. (2017). La etapa kirchnerista. Nuevo 'momento constitutivo' entre movimientos sociales y Estado en Argentina. Sociohistórica (39), pp. 1-28. Disponible en http://www.sociohistorica. fahce.unlp.edu.ar/article/view/SHe023/8413 (2013). El escenario y sus actores: Ciclos políticos institucionales y ejes de acumulación en el Frente Popular Darío Santillán (2004-2013). Ponencia presentada en las VII Jornadas de Jóvenes Investigadores del Instituto de Investigaciones Gino Germani. Facultad de 
Ciencias Sociales, Universidad de Buenos Aires, Buenos Aires.

Natalucci, A. y Pagliarone, M. F. (2013). Revisitando los conceptos de los social y lo político: movimientos sociales, procesos de democratización y nuevas institucionalidades. Revista Andina de Estudios Políticos, 3(2), pp. 77-98. Disponible en http://www.iepa.org.pe/raep/index.php/ ojs/article/view/38/30

(2011). Entre la movilización y la institucionalización. Los dilemas de los movimientos sociales (Argentina, 2001-2010). Polis (28), pp. 1-17.

Ogando, M. (2011). Nueva izquierda y disputa institucional. Una incitación a la incomodidad. Revista Batalla de Ideas, 2 (2), pp. 152-165.

Palomino, H. (2004). La política y lo político en los movimientos sociales en Argentina. Disponible en http:// departamento.pucp.edu.pe/ciencias-sociales/sociologia/sociologia-publicaciones/sociologia-documentos/la-politica-y-lo-politico-en-los-movimientos-sociales-en-argentina] (consultado en noviembre de 2016).

Palumbo, M.M. (2017). Dinámicas de construcción de subjetividades políticas y epistémicas en dispositivos pedagógicos de formación política. Un estudio en movimientos populares multisectoriales del Área Metropolitana de Buenos Aires (2011-2015) (Tesis de Doctorado en Ciencia de la Educación). Facultad de Filosofía y Letras, Universidad de Buenos Aires, Argentina (mimeo).

(2014). Las prácticas político-pedagógicas de los movimientos populares urbanos. El caso del Movimiento Popular La Dignidad en la Ciudad Autónoma de Buenos Aires (2012-2013) (Tesis de Maestría en Educación. Pedagogías Críticas y Problemáticas Socioeducativas). Facultad de Filosofía y Letras, Universidad de Buenos Aires, Argentina (mimeo).
Quijano, A. (2000). Colonialidad del poder, eurocentrismo y América Latina. Lander, E. (comp.) La colonialidad del saber: eurocentrismo y ciencias sociales. Perspectivas Latinoamericanas. Buenos Aires: CLACSO, pp- 201-246.

Rancière, J. (2012). El desacuerdo. Política y filosofía. Buenos Aires: Nueva Visión.

Sidicaro, R. (2011). El partido peronista y los gobiernos kirchneristas. Nueva Sociedad (234), pp. 7494.

Stefanazzi Kondolf, R., Mosquera, M. y Spadavecchia, G. (2015). Sobre la cuestión organizativa: hacia una nueva herramienta política. Ensayos políticos. Debates en torno al poder, la organización y la etapa. AA. VV (auts.). Buenos Aires: El Colectivo.

Svampa, M. (2010). Movimientos sociales, matrices sociopolíticas y nuevos escenarios en América Latina. Working Paper, 1. Disponible en https:// kobra.bibliothek.uni-kassel.de/bitstream/ urn:nbn:de:hebis:34-2010110334865/1/ OWP_Working_Paper_2010_01.pdf (consultado en septiembre de 2017).

y Pereyra, S. (2004). Entre la ruta y el barrio. La experiencia de las organizaciones piqueteras. Buenos Aires: Biblos.

Tapia, L. (2011). Política Salvaje. Buenos Aires: CLACSOWaldhuter. 